\title{
RESEARCH
}

Open Access

\section{Prevalence of molecular markers of drug resistance in an area of seasonal malaria chemoprevention in children in Senegal}

\author{
Aminata C Lo ${ }^{1 *}$, Babacar Faye ${ }^{1}$, El-Hadj Ba ${ }^{3}$, Badara Cisse ${ }^{1,2}$, Roger Tine ${ }^{1}$, Annie Abiola ${ }^{1}$, Magatte Ndiaye ${ }^{1}$, \\ Jean LA Ndiaye ${ }^{1}$, Daouda Ndiaye ${ }^{1}$, Cheikh Sokhna ${ }^{3}$, Jules F Gomis ${ }^{1}$, Yemou Dieng ${ }^{1}$, Omar Faye ${ }^{1}$, Omar Ndir ${ }^{1}$, \\ Paul Milligan², Matthew Cairns ${ }^{2}$, Rachel Hallett ${ }^{2}$, Colin Sutherland ${ }^{2}$ and Oumar Gaye ${ }^{1}$
}

\begin{abstract}
Background: In sub-Saharan Africa, malaria is the leading cause of morbidity and mortality especially in children. In Senegal, seasonal malaria chemoprevention (SMC) previously referred to as intermittent preventive treatment in children (IPTC) is a new strategy for malaria control in areas of high seasonal transmission. An effectiveness study of SMC, using sulphadoxine-pyrimethamine (SP) plus amodiaquine (AQ), was conducted in central Senegal from 2008 to 2010 to obtain information about safety, feasibility of delivery, and cost effectiveness of SMC. Here are report the effect of SMC delivery on the prevalence of markers of resistance to SP and AQ.

Methods: This study was conducted in three health districts in Senegal with 54 health posts with a gradual introduction of SMC. Three administrations of the combination AQ + SP were made during the months of September, October and November of each year in children aged less than 10 years living in the area. Children were surveyed in December of each year and samples (filter paper and thick films) were made in 2008, 2009 and 2010. The prevalence of mutations in the pfdhfr, pfdhps, pfmdr1 and pfcrt genes was investigated by sequencing and RTPCR in samples positive by microscopy for Plasmodium falciparum.

Results: Mutations at codon 540 of pfdhps and codon 164 of pfdhfr were not detected in the study. Among children with parasitaemia at the end of the transmission seasons, the CVIET haplotypes of pfcrt and the $86 \mathrm{Y}$ polymorphism of pfmdr1 were more common among those that had received SMC, but the number of infections detected was very low and confidence intervals were wide. The overall prevalence of these mutations was lower in SMC areas than in control areas, reflecting the lower prevalence of parasitaemia in areas where SMC was delivered.

Conclusion: The sensitivity of $P$. falciparum to SMC drugs should be regularly monitored in areas deploying this intervention. Overall the prevalence of genotypes associated with resistance to either SP or AQ was lower in SMC areas due to the reduced number of parasitaemia individuals.
\end{abstract}

Keyswords: Plasmodium falciparum, SMC, Sulphadoxine-pyrimethamine, Amodiaquine, Prevalence, Pfdhfr, Pfdhps, Pfcrt, Pfmdr1

\footnotetext{
* Correspondence: amlosn@yahoo.fr

${ }^{1}$ Service of Parasitology, Faculty of Medicine, University Cheikh Anta Diop, Dakar, Senegal

Full list of author information is available at the end of the article
} 


\section{Background}

In many parts of sub-Saharan Africa, malaria remains the leading cause of morbidity and mortality in children. Malaria caused an estimated 216 million cases of clinical malaria and 655 thousand deaths in 2010 [1]. In areas of seasonal malaria transmission, the burden of severe disease and mortality due to malaria is mainly among children under five years of age. Seasonal malaria chemoprevention (SMC) previously referred to as intermittent preventive treatment in children (IPTc), is a new control strategy suited to areas of high seasonal transmission. SMC is defined as the intermittent administration of full treatment of an anti-malarial medicine during the malaria season to prevent malarial illness with the objective of maintaining therapeutic anti-malarial drug concentrations in the blood throughout the period of greatest malarial risk [2].The World Health Organization now recommends that children living in areas of high seasonal transmission should receive treatment with sulphadoxinepyrimethamine (SP) plus amodiaquine (AQ) each month for up to four months during the peak transmission period. SP and AQ currently retain their efficacy in areas where SMC is recommended but it is important that sensitivity of parasites to SMC drugs is monitored in areas where it is introduced.

The presence of Plasmodium falciparum dihydrofolate reductase (pfdhfr) triple mutation (codon 108, 51 and 59) together with double $P$. falciparum dihydropteorate synthetase (pfdhps) mutations at codons 437 and 540 is associated with resistance to SP [3,4]. In West Africa, the mutation at codon 540 of the pfdhps is very rare and its presence is a useful single marker of quintuple mutation (triple $p f d h f r$ plus double $p f d h p s$ ). In addition to markers of resistance to SP, mutations at $P$. falciparum chloroquine transporter ( $p f c r t)$ and $P$. falciparum multidrug resistance $(p f m d r 1)$ genes should be assessed to monitor $\mathrm{SP}+\mathrm{AQ}$ efficacy in areas where SMC is implemented. The pfcrt mutant haplotype (CVIET) based on codon 72-76, which mediates high levels of resistance to chloroquine (CQ), has been linked with moderate resistance to AQ in Africa in the presence of particular haplotypes of $\mathrm{p} f m d r 1[5,6]$. IPTi in infants in Senegal with SP revealed that despite an increase in the prevalence of individual mutations, there was no major impact on dihydrofolate reductase (pfdhfr) and dihydropteroate synthetase (pfdhps) combined mutations [7].

In this study, the prevalence of molecular markers of $p f c r t$ and $p f m d r 1$ was determined to evaluate the effectiveness of the use of $A Q$, as in several studies in Mali $[8,9]$. The aim of this study was to assess the prevalence of molecular markers of resistance to SP ( $p f d h f r$ and pfdhps) and AQ (pfcrt and pfmdr1) in an area where SMC using both drugs was being implemented at large scale.

\section{Methods}

\section{Study site and subjects}

According to the 2002 national census, approximately 450,000 people live in this area. The northern part of the study area is part of the district medical Bambey while the southern part of the district medical Fatick. There are approximately 725 villages in the study area and 54 health posts run by health workers and two health centers directed by a medical doctor.

The study site and the implementation of SMC are described by Cisse et al. [10]. In brief, SMC with SP+AQ was administered once per month from September to November to children in three districts in central Senegal (Mbour, Bambey and Fatick) from 2008 to 2010. Implementation of SMC was phased in the 54 health posts. Nine health posts delivered SMC in 2008, 27 health posts in 2009, and 45 in 2010. Initially children aged three to 59 months were included in the programme; in 2009 the upper age limit was increased to include all children less than 10 years of age.

At the end of each transmission season, a crosssectional survey of children was conducted to measure the prevalence of parasitaemia and to take blood samples on filter paper for analysis of molecular markers of resistance to SMC drugs. In 2008, the population in the catchment of 27 health posts was surveyed, including the nine health posts that delivered SMC, and 18 control health posts that did not deliver SMC. In 2009 and 2010, all 54 health posts were included in the survey. Sampling was stratified by health post area, with probably sampling of individuals within each stratum.

For each child signed consent was obtained from a parent or guardian after explaining the aims and procedures of the survey. Filter paper samples from individuals who had a positive blood film for P. falciparum were used to determine the presence of mutations in genes pfdhfr, pfdhps, pfmdrl and pfcrt associated with resistance to SP and to AQ by sequencing and Real Time PCR, to measure the impact of SMC on the prevalence of these mutations at the end of each transmission season.

\section{Ethical approval}

The study was approved by the Ethics Committees of the Ministry of Health, Senegal and the London School of Hygiene \& Tropical Medicine.

\section{Laboratory methods Microscopy}

Thick smears were stored at room temperature for 48 hours, washed with pierval water, $\mathrm{pH} 7.2$ and stained in a 6\% Giemsa solution for 20 minutes. Microscopy was used to detect absence or presence of asexual and sexual parasites. Total number of parasites seen and total number of white blood cells (WBCs) counted were used to 
work out parasitaemia per $\mu \mathrm{l}$ assuming that $1 \mu \mathrm{l}$ contains 8,000 WBCs. Quality control was performed by reading $10 \%$ of all slides by a different experienced laboratory technician; in case of discrepancies a third reading was performed and the average results obtained with the two closest.

\section{DNA extraction}

The genomic DNA of the parasite was extracted from filter papers reported positive after microscopic examination using the chelex method according to methods described by Plowe et al. [11] and K76T was determined in at least two multiplex real-time PCR runs using the Rotorgene 3000 platform previously described [12]. 3D7, Dd2 and 7G8 DNA obtained from the Malaria Research Reagent Resource (MR4) were used to provide sequencespecific positive control.

\section{Genotyping}

The genotype of the $p f c r t$ gene for polymorphisms C72S and $\mathrm{K} 76 \mathrm{~T}$ was determined in at least two multiplex realtime PCR runs using the Rotorgene 3000 platform previously described [8]. 3D7, Dd2 and 7G8 DNA obtained from the Malaria Research Reagent Resource (MR4) were used to provide sequence-specific positive control.

Amplification of pfdhfr, pfdhps and pfmdrl genes involved primers is described in Table 1 . All amplicons of the $p f d h f r, p f d h p s$ and $p f m d r 1$ genes were re-amplified on a nested PCR step. Amplicons from nested PCR reaction were purified using the QIA quick PCR Purification Kit according to manufacturer's instructions and subjected to di-deoxy fluorescent sequencing (Big Dye 3.1) using conditions and sequencing primers pairs. The sequence of amplified DNA products was determined using ABI PRISM Genetic Analyser. Chromas software was used to analyse the sequence results. The DNA sequence was compared with reference sequence of the $p f d h f r$, pfdhps and pfmdr1 portions of the P. falciparum 3D7 clone using Blast similar alignment. Primers sequences are summarized in Table 1.

\section{Statistical methods}

For each mutation, are estimated the proportion, $\mathrm{p}_{1}$, of genotyped samples that were positive for the mutation, and its standard error, taking account of the different survey design used in each year using the survey commands in Stata 12 (StataCorp, College Station, Texas). The prevalence of parasitaemia $\mathrm{p}_{2}$ are also estimated, and its standard error. The prevalence of the different mutations in the population were then estimated, based on the prevalence of the mutation among genotyped samples, and the overall prevalence of parasitaemia, i.e. as $\mathrm{p}=\mathrm{p}_{1} \times \mathrm{p}_{2}$, the standard error for $\log (\mathrm{p})$ obtained by the delta method was used to calculate $95 \%$ confidence interval. Comparisons between intervention and control areas were made by calculating the prevalence ratio, again using the delta method for calculating standard errors. Due to secular changes in prevalence of mutations in the study area over time the year of sampling could act as a confounder of the association between SMC and the prevalence of mutations. Consequently, when comparing prevalence of mutations over the entire study period (shown in Table 5), are accounted for the fact that more health posts implemented SMC later in the study (9/54 in 2008, 27/54 in 2009, 45/54 in 2010). By adjusting for study year in the binomial regression model used to estimate the prevalence ratios.

\section{Results}

Of the 2,721 children surveyed in 2008, blood samples were obtained from 2,705 children. 84 were positive for $P$. falciparum after microscopic examination of slides, $18 / 1,019$ (1.8\%) in the SMC area and 66/1,686 (3.9\%) in the control area (survey-adjusted prevalence ratio 0.30 (95\% CI: 0.15, 0.61), $\mathrm{p}=0.001$ ). In 2009, 6809 children were surveyed, samples were obtained from 6,646, of which 50 had positive blood films, 9/3,326 (0.27\%) and $41 / 3320$ (1.2\%) respectively in the SMC and control areas; aPR $0.16(0.06,0.42), \mathrm{p}<0.001$. In 2010, 1,098 were surveyed, samples were obtained for 1,098 children, of which 27 were positive by microscopy, 21/882 (2.4\%) and $6 / 216(2.8 \%)$ respectively in the SMC and control areas, aPR $0.71(0.23,2.20), \mathrm{p}=0.55$.

\section{Pfdhfr polymorphisms}

In 2008, 45 of 84 samples, all samples (43 and 27) in 2009 and 2010 were positive for P. falciparum by PCR. The prevalence of IRNI triple-mutant haplotypes of pfdhfr in 2008 stood at 7/8 (87.5\%) in SMC villages versus $27 / 37(72.9 \%)$ in control villages (survey-adjusted p-value $=0.002)$. In 2009, the prevalence was $4 / 6(66.6 \%)$ in intervention villages and $27 / 34(79.4 \%)$ in control villages $(\mathrm{p}=0.50)$. In 2010 , the prevalence of IRNI triplemutant was 19/21 (90.4\%) and 4/4 (100\%) in SMC villages and control villages respectively $(\mathrm{p}=0.46)$. The allele I164L mutation was not found among Senegalese isolates (Tables 2, 3, 4).

\section{Pfdhps polymorphisms}

All the 2008, 2009 and 2010 samples were wild-type for the 540 codon of pfdhps. The prevalence of mutation of pfdhps $437 \mathrm{G}$ allele was $7 / 8$ (87.5\%) in SMC villages versus $25 / 37(67.56 \%)$ in control villages during the first year $(\mathrm{p}=0.50)$. After two and three years of implementation, prevalence was $4 / 6(66.6 \%)$ and $18 / 21$ (85.7\%) in SMC villages and 25/35 (71.4) and 4/4 (100\%) in control villages, respectively ( $\mathrm{p}=0.88$ and $\mathrm{p}=0.48$ respectively). The $p f d h f r / p f d h p s$ IRNI/GK quadruple mutant was $6 / 8$ 
Table 1 Pfdhfr, pfdhps, pfmdr1 and pfcrt PCR primers sequences used in amplification reactions

\begin{tabular}{|c|c|c|c|c|}
\hline Genes names & $\begin{array}{l}\text { Primers } \\
\text { names }\end{array}$ & Primers sequences & $\begin{array}{l}\text { amplicon } \\
\text { size (bp) }\end{array}$ & PCR cycling conditions \\
\hline \multicolumn{5}{|l|}{ Pfdhfr } \\
\hline PCR1 & dhfr_M1 & 5'-TTATGATGGAACAAGTCTGC-3' & 650 & $\begin{array}{l}93^{\circ} \mathrm{C} \text { for } 5 \mathrm{~min} /\left(94^{\circ} \mathrm{C} \text { for } 30 \mathrm{~s}-54^{\circ} \mathrm{C} \text { for } 60 \mathrm{~s}-65^{\circ} \mathrm{C} \text { for } 60 \mathrm{~s}\right) \times \\
41 \mathrm{cycles} / 65^{\circ} \text { for } 5 \mathrm{~min} / 15^{\circ} \mathrm{C} \text { for } 5 \mathrm{~min}\end{array}$ \\
\hline \multirow[t]{2}{*}{ Nested } & dhfr_M7 & 5'-CTAGTATATACATCGCTAACA-3' & & \\
\hline & dhfr-M9 & 5'-CTGGAAAAAATACATCACATTCATATG-3' & 594 & $\begin{array}{l}95^{\circ} \mathrm{C} \text { for } 5 \mathrm{~min} /\left(93^{\circ} \mathrm{C} \text { for } 30 \mathrm{~s}-56^{\circ} \mathrm{C} \text { for } 30 \mathrm{~s}-68^{\circ} \mathrm{C} \text { for } 75 \mathrm{~s}\right) \times \\
30 \text { cycles } / 75^{\circ} \mathrm{C} \text { for } 5 \mathrm{~min}\end{array}$ \\
\hline \multirow[t]{3}{*}{ Sequencing } & dhfr-M3 & 5'-TGATGGAACAAGTCTGCGACGTT-3' & & \\
\hline & dhfr-M9 & 5'-CTGGAAAAAATACATCACATTCATATG-3' & & $\begin{array}{l}96^{\circ} \mathrm{C} \text { for } 1 \mathrm{~min} /\left(96^{\circ} \mathrm{C} \text { for } 30 \mathrm{~s}-50^{\circ} \mathrm{C} \text { for } 30 \mathrm{~s}-60^{\circ} \mathrm{C} \text { for } 4 \mathrm{~min}\right) \times \\
26 \text { cycles } / 4^{\circ} \mathrm{C} \text { hold until ready to purify }\end{array}$ \\
\hline & dhfr-M3 & 5'-TGATGGAACAAGTCTGCGACGTT-3' & & \\
\hline \multicolumn{5}{|l|}{ Pfdhps } \\
\hline \multirow[t]{2}{*}{ PCR1 } & dhps-N1 & 5'-GATTCTTTTTCAGATGGAGG-3' & 770 & $\begin{array}{l}94^{\circ} \mathrm{C} \text { for } 3 \mathrm{~min} /\left(94^{\circ} \mathrm{C} \text { for } 30 \mathrm{~s}-55^{\circ} \mathrm{C} \text { for } 30 \mathrm{~s}-65^{\circ} \mathrm{C} \text { for } 60 \mathrm{~s}\right) \times \\
30 \text { cycles } / 65^{\circ} \mathrm{C} \text { for } 5 \mathrm{~min} / 15^{\circ} \mathrm{C} \text { for } 5 \mathrm{~min} \text {. }\end{array}$ \\
\hline & dhps-N2 & 5'-TTCCTCATGTAATTCATCTGA-3' & 711 & \\
\hline \multirow[t]{3}{*}{ Nested } & dhps-R2 & 5'-AACCTAAACGTGCTGTTCAA-3' & & $\begin{array}{l}94^{\circ} \mathrm{C} \text { for } 5 \mathrm{~min} /\left(94^{\circ} \mathrm{C} \text { for } 30 \mathrm{~s}-60^{\circ} \mathrm{C} \text { for } 30 \mathrm{~s}-65^{\circ} \mathrm{C} \text { for } 1 \mathrm{~min}\right) \times \\
30 \text { cycles } / 65^{\circ} \mathrm{C} \text { for } 5 \mathrm{~min} / 15^{\circ} \mathrm{C} \text { for } 5 \mathrm{~min} \text {. }\end{array}$ \\
\hline & dhps-R/ & 5'-AATTGTGTGATTTGTCCACAA-3' & & \\
\hline & dhps-R2 & 5'-AACCTAAACGTGCTGTTCAA-3' & & $\begin{array}{l}96^{\circ} \mathrm{C} \text { for } 1 \mathrm{~min} /\left(96^{\circ} \mathrm{C} \text { for } 30 \mathrm{~s}-50^{\circ} \mathrm{C}-60^{\circ} \mathrm{C} \text { for } 4 \mathrm{~min}\right) \times \\
26 \text { cycles } / 4^{\circ} \mathrm{C} \text { hold until ready to purify. }\end{array}$ \\
\hline Sequencing & dhps-R/ & 5'-AATTGTGTGATTTGTCCACAA-3' & & \\
\hline \multicolumn{5}{|l|}{ Pfmdr1 } \\
\hline \multirow[t]{2}{*}{ PCR1 } & $\mathrm{fn} 1 / 1$ & 5'-ACAAAAAGAGTACCGCTGAAT-3' & 578 & $\begin{array}{l}94^{\circ} \mathrm{C} \text { for } 3 \mathrm{~min} /\left(94^{\circ} \mathrm{C} \text { for } 30 \mathrm{~s}-55^{\circ} \mathrm{C} \text { for } 30 \mathrm{~s}-65^{\circ} \mathrm{C} \text { for } 1 \mathrm{~min}\right) \times \\
30 \text { cycles } / 65^{\circ} \mathrm{C} \text { for } 5 \mathrm{~min} / 15^{\circ} \mathrm{C} \text { for } 5 \mathrm{~min} \text {. }\end{array}$ \\
\hline & $\mathrm{rev} / \mathrm{c} 1$ & 5'-AAACGCAAGTAATACATAAAGTC-3' & 534 & \\
\hline \multirow[t]{2}{*}{ Nested } & $\mathrm{mdr} 2 / 1$ & 5'-ACAAAAAGAGTACCGCTGAAT-3' & & $\begin{array}{l}94^{\circ} \mathrm{C} \text { for } 3 \mathrm{~min} /\left(94^{\circ} \mathrm{C} \text { for } 30 \mathrm{~s}-60^{\circ} \mathrm{C} \text { for } 30 \mathrm{~s}-65^{\circ} \mathrm{C} \text { for } 1 \mathrm{~min}\right) \times \\
30 \text { cycles } / 65^{\circ} \mathrm{C} \text { for } 5 \mathrm{~min} / 15^{\circ} \mathrm{C} \text { for } 5 \mathrm{~min} \text {. }\end{array}$ \\
\hline & newrev1 & 5'-AAACGCAAGTAATACATAAAGTC-3' & & \\
\hline \multirow[t]{2}{*}{ Sequencing } & mdrfrif-seq & 5'-GTCGAATTATTTAGAAAAAT-3' & & $\begin{array}{l}96^{\circ} \mathrm{C} \text { for } 1 \mathrm{~min} /\left(96^{\circ} \mathrm{C} \text { for } 30 s^{-} 50^{\circ} \mathrm{C}-60^{\circ} \mathrm{C} \text { for } 4 \mathrm{~min}\right) \times \\
26 \text { cycles } / 4^{\circ} \mathrm{C} \text { hold until ready to purify. }\end{array}$ \\
\hline & mdrfr1r-seq & 5'-GCAAGTAATACATAAAGT-3' & & \\
\hline \multicolumn{5}{|l|}{ Pfcrt } \\
\hline & Crtd1 & 5'-TGTGCTCATGTGTTTAAACTT 5'- & 166 & $\begin{array}{l}94^{\circ} \mathrm{C} \text { for } 3 \mathrm{~min} /\left(94^{\circ} \mathrm{C} \text { for } 30 \mathrm{~s}-55^{\circ} \mathrm{C} \text { for } 30 \mathrm{~s}-65^{\circ} \mathrm{C} \text { for } 1 \mathrm{~min}\right) \times \\
30 \mathrm{cycles} / 65^{\circ} \mathrm{C} \text { for } 5 \mathrm{~min} / 15^{\circ} \mathrm{C} \text { for } 5 \mathrm{~min} \text {. }\end{array}$ \\
\hline & Crtd2 & CAAAACTATAGTTACCAATTITG & & \\
\hline
\end{tabular}

(75\%), 4/6 (66.6\%) and 18/21 (85.7\%) in SMC villages and $23 / 37$ (62.1), 23/34 (67.6\%) and $4 / 4(100 \%)$ in control villages in 2008, 2009 and 2010, respectively (all p-values $>0.2$ ).

\section{Pfcrt polymorphisms}

The pfcrt haplotypes CVIET and CVMNK were successfully identified in 38 samples in 2008, 41 samples in 2009 and 27 samples in 2010. Prevalence of CVIET haplotypes in intervention villages was $2 / 3(66.6 \%)$ in 2008 , versus $8 / 35(22.8 \%)$ in control villages $(\mathrm{p}=0.038)$. It was $3 / 6(50 \%)$ and 13/35 (37.1\%), respectively, in SMC villages and control villages in $2009(\mathrm{p}=0.55)$. In 2010 the CVIET haplotypes was found in $8 / 22(36.3 \%)$ of positive samples in SMC villages versus 2/5 (40\%) in control villages $(\mathrm{p}=0.72)($ Tables $2,3,4)$.

\section{Pfmdr1 polymorphisms}

Twenty-four samples from 2008, 40 samples from 2009 and 27 isolates from 2010 were successfully genotyped for $p f m d r 1$ at codon 86 and 184. In 2008, prevalence of the mutation pfmdr1-86Y allele was $1 / 5$ (20\%) in SMC villages, with no mutation was found at codon 86 in control villages $(p=0.066)$. In 2009 , the prevalence was 4/6 (66.6\%) in SMC villages and 15/33 (45.4\%) in control villages $(\mathrm{p}=0.03)$. In 2010 , the $86 \mathrm{Y}$ mutation was observed in 12/22 (54.5\%) and no mutation in control villages $(p=0.051)$. During the first year, mutant $184 \mathrm{~F}$ 
Table 2 Prevalence of resistance mutations in 2008 among those typed and estimated prevalence in the population

\begin{tabular}{|c|c|c|c|c|c|c|}
\hline & \multicolumn{2}{|c|}{ Study samples } & \multicolumn{3}{|c|}{ Prevalence in population $\$$} & \multirow{3}{*}{ p-value } \\
\hline & \multirow[t]{2}{*}{ Control area } & \multirow[t]{2}{*}{ SMC area } & \multirow[t]{2}{*}{ Control area } & \multirow[t]{2}{*}{ SMC area } & Prevalence ratio $\wedge$ & \\
\hline & & & & & $\overline{\text { SMC/ non SMC }(95 \% \mathrm{Cl})}$ & \\
\hline Prevalence of parasitaemia: & $66 / 1686$ & $18 / 1019$ & 4.86 & 1.46 & $0.30(0.15,0.61)$ & 0.001 \\
\hline \multicolumn{7}{|l|}{ Prevalence of mutations } \\
\hline dhfr triple $(51,59,108)$ & $27 / 37$ & $7 / 8$ & 2.88 & 1.55 & $0.54(0.25,1.17)$ & 0.12 \\
\hline dhps-437 & $25 / 37$ & $7 / 8$ & 2.68 & 1.55 & $0.58(0.25,1.34)$ & 0.20 \\
\hline $\begin{array}{l}\text { SP resistant mutant } \\
\text { (dhfr triple }+ \text { dhps 437) }\end{array}$ & $23 / 37$ & $6 / 8$ & 2.47 & 1.32 & $0.54(0.22,1.30)$ & 0.17 \\
\hline crt CVIET mutation & $8 / 35$ & $2 / 3$ & 0.87 & 1.18 & $1.36(0.39,4.71)$ & 0.63 \\
\hline $\mathrm{mdr} 86 \mathrm{Y}$ & $0 / 19$ & $1 / 5$ & 0 & 0.35 & - & - \\
\hline mdr $184 \mathrm{~F}$ & $13 / 19$ & $4 / 5$ & 2.74 & 1.41 & $0.52(0.23,1.14)$ & 0.10 \\
\hline $\begin{array}{l}\text { AQ resistant mutant } \\
(\mathrm{mdr} 86 \mathrm{Y}+\mathrm{crt} \text { CVIET) }\end{array}$ & $0 / 13$ & $1 / 2$ & 0 & 0.88 & - & - \\
\hline SP resistant \& AQ resistant & $0 / 11$ & $1 / 2$ & 0 & 0.88 & - & - \\
\hline
\end{tabular}

$\wedge$ Prevalence ratios accounting for survey design. \$For genotypes, prevalence among population is estimated as the product of 1) the probability of a resistant genotype among the typed samples and 2) the probability positive among samples with a definitive result (positive or negative) for asexual stage parasitaemia. Standard errors estimated by the delta method as described in the methods section.

alleles were found in 4/5 (80) and 13/19 (68.4) SMC and control villages, respectively $(\mathrm{p}=0.33)$. In 2009 , prevalence of this mutation was 5/6 (83.3) and 28/34 in SMC and control villages $(\mathrm{p}=0.74)$. In 2010 , this was $15 / 22$ (68.1) and 2/5 in 2010, ( $\mathrm{p}=0.56)$ (Tables $2,3,4)$.

\section{Discussion}

Malaria remains a major concern in Senegal, despite the significant reduction in disease incidence observed in parts of the country in recent years (according to data of the National Malaria Control Programme of Senegal). It has become urgent to find a new strategy for the prevention of malaria especially among children less than ten years residing in areas of seasonal malaria, for which the risk of dying from malaria remains high. SMC with $\mathrm{SP}+\mathrm{AQ}$ is now recommended by $\mathrm{WHO}$ for the control of malaria in areas of the Sahel and sub-Sahel with high seasonal malaria transmission. However, the long-term sustainability of SMC will depend on sensitivity of parasites to the anti-malarial drugs used. In this study, the impact of the use of $\mathrm{SP}+\mathrm{AQ}$ over the course of three years are measured, on an increasingly large scale, on

Table 3 Prevalence of resistance mutations in 2009 among those typed and estimated prevalence in the population

\begin{tabular}{|c|c|c|c|c|c|c|}
\hline & \multicolumn{2}{|c|}{ Study samples } & \multicolumn{3}{|c|}{ Prevalence in population $\$$} & \multirow{3}{*}{ p-value } \\
\hline & \multirow[t]{2}{*}{ Control area } & \multirow[t]{2}{*}{ SMC area } & \multirow{2}{*}{$\begin{array}{l}\text { Control } \\
\text { area }(\%)\end{array}$} & \multirow{2}{*}{$\begin{array}{l}\text { SMC } \\
\text { area (\%) }\end{array}$} & \multirow{2}{*}{$\frac{\text { Prevalence ratio^ }}{\text { SMC/ non SMC }(95 \% \mathrm{Cl})}$} & \\
\hline & & & & & & \\
\hline $\begin{array}{l}\text { Prevalence of parasitaemia } \\
\text { among children surveyed }\end{array}$ & $41 / 3320$ & 9/3326 & 1.33 & 0.22 & $0.16(0.06,0.42)$ & $<0.001$ \\
\hline \multicolumn{7}{|c|}{ Prevalence of mutations among typed } \\
\hline dhfr triple $(51,59,108)$ & $27 / 34$ & $4 / 6$ & 0.98 & 0.18 & $0.18(0.059,0.58)$ & 0.004 \\
\hline dhps-437 & $25 / 35$ & $4 / 6$ & 0.88 & 0.18 & $0.21(0.064,0.66)$ & 0.008 \\
\hline $\begin{array}{l}\text { SP resistant mutant } \\
\text { (dhfr triple }+ \text { dhps 437) }\end{array}$ & $23 / 34$ & $4 / 6$ & 0.84 & 0.18 & $0.22(0.068,0.69)$ & 0.01 \\
\hline crt CVIET mutation & $13 / 35$ & $3 / 6$ & 0.46 & 0.14 & $0.30(0.10,0.86)$ & 0.026 \\
\hline mdr $86 Y$ & $15 / 33$ & $4 / 6$ & 0.56 & 0.18 & $0.32(0.11,0.92)$ & 0.034 \\
\hline mdr 184F & $28 / 34$ & $5 / 6$ & 1.02 & 0.23 & $0.22(0.086,0.58)$ & 0.002 \\
\hline $\begin{array}{l}\text { AQ resistant mutant } \\
(\mathrm{mdr} 86 \mathrm{Y}+\mathrm{crt} \text { CVIET) }\end{array}$ & $9 / 33$ & $2 / 6$ & 0.34 & 0.09 & $0.27(0.078,0.92)$ & 0.036 \\
\hline SP resistant \& AQ resistant & $8 / 32$ & $2 / 6$ & 0.31 & 0.09 & $0.29(0.08,1.07)$ & 0.064 \\
\hline
\end{tabular}

$\wedge$ Prevalence ratios accounting for survey design. \$For genotypes, prevalence among population is estimated as the product of 1) the probability of a resistant genotype among the typed samples and 2) the probability positive among samples with a definitive result (positive or negative) for asexual stage parasitaemia. Standard errors estimated by the delta method as described in the methods section. 
Table 4 Prevalence of resistance mutations in 2010 among those typed and estimated prevalence in the population

\begin{tabular}{|c|c|c|c|c|c|c|}
\hline & \multicolumn{2}{|l|}{ Study samples } & \multicolumn{3}{|c|}{ Prevalence in population $\$$} & \multirow{3}{*}{ p-value } \\
\hline & \multirow[t]{2}{*}{ Control area } & \multirow[t]{2}{*}{ SMC area } & \multirow[t]{2}{*}{ Control area } & \multirow[t]{2}{*}{ SMC area } & Prevalence ratio $\wedge$ & \\
\hline & & & & & $\overline{\text { SMC/ non SMC (95\% Cl) }}$ & \\
\hline Prevalence of parasitaemia: & $6 / 216$ & $21 / 882$ & 2.47 & 1.76 & $0.71(0.23,2.20)$ & 0.55 \\
\hline \multicolumn{7}{|l|}{ Prevalence of mutations } \\
\hline dhfr triple $(51,59,108)$ & $4 / 4$ & $19 / 21$ & 2.78 & 2.15 & $0.78(0.30,1.98)$ & 0.60 \\
\hline dhps-437 & $4 / 4$ & $18 / 21$ & 2.78 & 2.04 & $0.74(0.28,1.90)$ & 0.52 \\
\hline $\begin{array}{l}\text { SP resistant mutant } \\
\text { (dhfr triple }+ \text { dhps 437) }\end{array}$ & $4 / 4$ & $18 / 21$ & 2.78 & 2.04 & $0.74(0.28,1.90)$ & 0.52 \\
\hline crt CVIET mutation & $2 / 5$ & $8 / 22$ & 1.11 & 0.87 & $0.78(0.15,4.09)$ & 0.77 \\
\hline mdr $86 \mathrm{Y}$ & $0 / 5$ & $12 / 22$ & 0 & 1.30 & - & - \\
\hline mdr 184F & $2 / 5$ & $15 / 22$ & 1.11 & 1.62 & $1.46(0.27,8.05)$ & 0.66 \\
\hline $\begin{array}{l}\text { AQ resistant mutant } \\
(\mathrm{mdr} 86 \mathrm{Y}+\mathrm{crt} \text { CVIET) }\end{array}$ & $0 / 5$ & $5 / 22$ & 0 & 0.54 & - & - \\
\hline $\mathrm{SP}$ resistant \& $\mathrm{AQ}$ resistant & $0 / 4$ & $5 / 21$ & 0 & 0.57 & - & - \\
\hline
\end{tabular}

$\wedge$ Prevalence ratios accounting for survey design. \$For genotypes, prevalence among population is estimated as the product of 1) the probability of a resistant genotype among the typed samples and 2) the probability positive among samples with a definitive result (positive or negative) for asexual stage parasitaemia. Standard errors estimated by the delta method as described in the methods section.

the prevalence of molecular markers of resistance in characterizing the prevalence of mutation in pfdhfr and pfdhps genes, associated with resistance to SP, and genes pfmdr 1 and pfcrt, markers of resistance to CQ and AQ.

Among children with parasitaemia at the end of the transmission season, the prevalence of mutation pfmdr1$86 \mathrm{Y}$ was higher among children that had received SMC. There was no strong evidence that the prevalence of other mutations, among infected children, was different in SMC and control areas. However, despite the large sample size of these surveys, the number of positives was low and confidence intervals were wide due to reduced transmission during the study period.

In each year, the overall prevalence of SP-resistant genotypes was lower in SMC areas, as a consequence of the marked reduction in prevalence of infection in areas using SMC. For pfcrt-CVIET in 2008 and pfmdr1-184F in 2010, point estimates of the prevalence ratio were above 1 , but in both cases the confidence in intervals were wide.

Differences in the absolute prevalence of resistance genotypes are seen most clearly in 2009, the year when there were an equal number of clusters in the intervention and control groups.

The presence of mutations at codons 540 of the pfdhps gene and 164 of the pfdhfr gene was not detected in this study. These mutations are considered as confirmed markers of resistance to SP, and appear associated with treatment failure in East Africa [13]. The high prevalence of the pfdhfr triple mutation (88/110 samples typed) and the pfdhfr / pfdhps quadruple mutation (83/111 samples) observed in this study is not very different from the results observed after two years of implementation of SMC with SP in infants in Senegal [7]. This is consistent with the results obtained in Gabon, in Senegal and in Cameroon [14-16].

Table 5 Prevalence of resistance mutations among children with parasitaemia pooled over the entire study

\begin{tabular}{|c|c|c|c|c|c|}
\hline Mutation & $\begin{array}{l}\text { Non-SMC area } n \\
\text { positive / } \mathrm{N} \text { typed (\%) }\end{array}$ & $\begin{array}{l}\text { SMC area } \mathrm{n} \text { positive / } \\
\mathrm{N} \text { typed }(\%)\end{array}$ & $\begin{array}{l}\text { Crude prevalence ratio } \\
\text { SMC/ non SMC (95\% CI) }\end{array}$ & $\begin{array}{l}\text { Adjusted prevalence ratio* } \\
\text { SMC/ non SMC }(95 \% \mathrm{Cl})\end{array}$ & p-value \\
\hline dhfr triple $(51,59,108)$ & $59 / 76(77.6)$ & 29/34 (85.3) & $1.10(0.91,1.32)$ & $0.90(0.79,1.02)$ & 0.087 \\
\hline dhps-437 & 55/77 (71.4) & $28 / 34(82.4)$ & $1.15(0.93,1.42)$ & $0.98(0.80,1.21)$ & 0.867 \\
\hline $\begin{array}{l}\text { SP resistant mutant } \\
\text { (dhfr triple }+ \text { dhps 437) }\end{array}$ & $51 / 76(67.1)$ & 27/34 (79.4) & $1.18(0.94,1.49)$ & $0.89(0.75,1.06)$ & 0.182 \\
\hline crt CVIET mutation & 23/76 (30.3) & $12 / 30(40.0)$ & $1.32(0.76,2.31)$ & $1.46(0.70,3.05)$ & 0.311 \\
\hline mdr $86 Y$ & $15 / 58(25.9)$ & $16 / 32(50.0)$ & $1.93(1.1,3.38)$ & $1.86(1.04,3.34)$ & 0.037 \\
\hline mdr 184F & $44 / 59(74.6)$ & 23/32 (71.9) & $0.96(0.74,1.26)$ & $1.09(0.82,1.47)$ & 0.550 \\
\hline $\begin{array}{l}\text { AQ resistant mutant } \\
(\mathrm{mdr} 86 \mathrm{Y}+\mathrm{crt} \text { CVIET) }\end{array}$ & $9 / 52(17.3)$ & $7 / 29(24.1)$ & $1.39(0.58,3.37)$ & $1.90(0.71,5.09)$ & 0.205 \\
\hline SP-AQ resistant & $8 / 48(16.7)$ & $7 / 28(25.0)$ & $1.50(0.61,3.72)$ & $2.04(0.73,5.67)$ & 0.173 \\
\hline
\end{tabular}

Prevalence ratios from binomial regression model with robust standard errors *Adjusted for year of the study as described in the statistical methods. 
The quadruple mutation was observed in 83/111 samples. Intergenic association of pfdhfr and pfdhps mutant codons was found in other studies where SP resistance was found to be associated with double up to quintuple mutations in both genes $[17,18]$.

The prevalence of $p f c r t$ CVIET among children positive at the end of the transmission season (10/38 in 2008, 16/ 41 in 2009 and 10/27 in 2010) is low compared to previous estimates; the prevalence of pfcrt mutation between 2004 and 2006 was about $60 \%$ in Senegal and Kenya $[19,20]$. This may be due to the fact that in Senegal, CQ has been abandoned as first-line drug treatment against malaria since 2002, first replaced with SP + AQ and from 2006 onwards with ACT. A substantial decrease in the prevalence of mutations at the level of the pfcrt gene several years after discontinuation of $C Q$ as the first-line drug was observed in Malawi by Kublin et al. [21] and Mita et al. [22]. Over three years of SMC, the results showed that the prevalence of $p f c r t$ and $p f m d r 1$ mutation was more frequent in SMC areas but the only significant difference was for $p f m d r 1-86 Y$. The association mutations pfcrt, pfindr1, pfdhfr and pfdhps were demonstrated by authors in West Africa and in Angola [23-25]. Almost all isolates carrying the mutant genotype for $p f d h f r$ or $p f d h p s$ (conferring resistance to SP), carry at least one of the mutations associated with AQ (pfcrt and or $p f m d r 1)$.

However, despite the high rates of mutations observed at these genes, SP and/or AQ remain effective for the treatment and prevention of malaria in West Africa [15,26-28]. The value of specific combinations of these molecular markers for the predicting efficacy of SMC needs to be established in settings with different levels of malaria transmission and acquired immunity [29]. However, defining a resistance threshold for acceptable efficacy may be problematic given that each SMC study will contribute only a single data point to examine this relationship, as was the case for studies of IPTi [30]. A limitation of this study is that prevalence of resistant markers was measured only in the target age group for SMC, and may not indicate changes in prevalence of the different resistance genotypes in the whole population.

The prevalence of different resistance genotypes at the end of the transmission season may simply represent differential survival of resistant parasites, which is necessary but not sufficient for SMC to lead to increased transmission of drug resistant genotypes. Also relevant will be the relative importance of children under five as a source of onward transmission in relation to adults and older children. Adults and older children will not receive SP+AQ for SMC and should not receive SP or AQ for treatment of symptomatic malaria where SMC is deployed. Consequently, because prevalence among children treated with SMC is much lower than among children who do not receive SMC, the fraction of the total population with SP and AQ resistant parasites will be lower than if SMC is not used. Monitoring among older children or adults was not undertaken in this study, but should be used as a means to monitor population-level changes in the prevalence of drug resistance markers in the future. Molecular analysis using DNA extracted from rapid diagnostic tests [31,32] would be one practical approach to measure these changes.

\section{Conclusion}

The dhfr-dhps quintuple mutation was not observed in either SMC or control health posts after three years of SMC implementation in the study area. Analysis of individual mutations showed that pfmdr1-86Y was more common among children positive for parasites at the end of the transmission season in SMC areas. However, the absolute prevalence of resistance markers was lower in SMC areas, reflecting the reduction in prevalence due to the intervention, and this is not expected to compromise the efficacy of regimens used for case management. Evaluation of the prevalence of markers of drug resistance should be part of routine monitoring and evaluation in areas where SMC is deployed.

\section{Competing interests}

The authors declared that they have no competing interests concerning the work reported in this paper.

\section{Authors' contributions}

$\mathrm{BC}, \mathrm{BF}$ and $\mathrm{PM}$ conceived and designed the study. $\mathrm{AL}$ was responsible of the molecular analysis and genotyping. MC and PM analysed the data. AL drafted the manuscript. All authors read and approved the final manuscript.

\section{Acknowledgements}

Bill \& Melinda Gates Fondation, Ministry of Health, London School of Hygiene and Tropical Medicine, Research for Development Institute, Communities of Mbour, Bambey and Fatick.

\section{Author details}

${ }^{1}$ Service of Parasitology, Faculty of Medicine, University Cheikh Anta Diop, Dakar, Senegal. 'London School of Hygiene and Tropical Medicine, London, UK. ${ }^{3}$ Institut de Recherche pour le Développement, Dakar, Senegal.

Received: 8 January 2013 Accepted: 7 April 2013

Published: 23 April 2013

\section{References}

1. WHO: World Malaria Report 2011. NLM Classification WC 765; 2011. Global Malaria Programme. ISBN ISBN 9789241564403.

2. WHO Policy recommandation: Seasonal Malaria Chemoprevention (SMC) for Plasmodium falciparum malaria control in highly seasonal transmission areas of the Sahel sub-regions in Africa. WHO Global Malaria Programme; 2012.

3. Kublin JG, Dzinjalamala FK, Kamwendo DD, Malkin EM, Cortese JF, Martino LM, Mukadam RA, Rogerson SJ, Lescano AG, Molyneux ME, Winstanley PA, Chimpeni P, Taylor TE, Plowe CV: Molecular markers for failure of sulfadoxine-pyrimethamine and chlorproguanil-dapsone treatment of Plasmodium falciparum malaria. J Infect Dis 2002, 185:380-388.

4. Plowe C: Folate antagonists and mechanisms of resistance. In Antimalarial chemotherapy: mechanisms of action, resistance, and new directions in drug discovery. Edited by Rosenthal PJ. Totowa, New Jersey: Humana Press; 2001:173-190.

5. Holmgren G, Gil JP, Ferreira PM, Veiga Ml, Obonyo C, Björkman A: Amodiaquine resistant Plasmodium falciparum malaria in vivo is associated with selection of pfcrt 76T and pfmdr1 86Y. Infect Genet Evol 2006, 6:309-314. 
6. Folarin OA, Bustamante C, Gbotosho GO, Sowunmi A, Zalis MG, Oduala AMJ, Happi CT: In vitro amodiaquine resistance and its association with mutation in pfcrt and pfmdr1 genes of $P$. falciparum isolates from Nigeria. Acta Trop 2011, 120:224-230.

7. Faye B, Ndiaye M, Ndiaye $J$, Annie A, Tine RC, Lo AC, Ndiaye M, Sow D, De Sousa A, Gaye O: Prevalence of molecular markers of Plasmodium falciparum resistance to sulfadoxine-pyrimethamine during the intermittent preventive treatment in infants coupled with the expanded program immunization in Senegal. Parasitol Res 2011, 109:133-138.

8. Dicko A, Diallo Al, Tembine I, Dicko Y, Dara N, Sidibe Y, Santara G, Diawara H, Conare T, Djimde A, Chandramohan D, Cousens S, Milligan PJ, Diallo DA Doumbo OK, Greenwood B: Intermittent preventive treatment of malaria provides substantial protection against malaria in children already protected by an insecticide-treated bednet in Mali: a randomised, double-blind, placebo-controlled trial. PLoS Med 2011, 8:e1000407.

9. Djimde A, Doumbo OK, Cortese JF, Kayentao K, Doumbo S, Diourte Y, Coulibaly D, Dicko A, Su XZ, Nomura T, Fidock DA, Wellems TE, Plowe CV: A molecular marker for chloroquine-resistant falciparum malaria. $N$ Engl J Med 2001, 344:257-263.

10. Cisse B, Sokhna C, Boulanger D, Milet J, Ba el H, Richardson K, Hallett R, Sutherland C, Simondon K, Simondon F, Alexander N, Gaye O, Targett G, Lines J, Greenwood B, Trape JF: Seasonal intermittent preventive treatment with artesunate and sulfadoxine-pyrimethamine for prevention of malaria in Senegalese children: a randomised, placebocontrolled, double-blind trial. Lancet 2006, 367:659-667.

11. Plowe CV, Djimde A, Bouare M, Doumbo O, Wellems TE: Pyrimethamine and proguanil resistance-conferring mutations in Plasmodium falciparum dihydrofolate reductase: polymerase chain reaction methods for surveillance in Africa. Am J Trop Med Hyg 1995, 52:565-568.

12. Gadalla NB, Elzaki SE, Mukhtar E, Warhurst DC, El-Sayed B, Sutherland CI: Dynamics of pfcrt alleles CVMNK and CVIET in chloroquine-treated Sudanese patients infected with Plasmodium falciparum. Malar J 2010, 9:74.

13. Sutherland CJ, Fifer $H$, Pearce RJ, bin Reza F, Nicholas M, Haustein T, Njimgye-Tekumafor NE, Doherty JF, Gothard P, Polley SD, Chiodini PL: Novel pfdhps haplotypes among imported cases of Plasmodium falciparum malaria in the United Kingdom. Antimicrob Agents Chemother 2009, 53:3405-3410.

14. Aubouy A, Jafari S, Huart V, Migot-Nabias F, Mayombo J, Durand R, Bakary M, Le Bras J, Deloron P: DHFR and DHPS genotypes of Plasmodium falciparum isolates from Gabon correlate with in vitro activity of pyrimethamine and cycloguanil, but not with sulfadoxine-pyrimethamine treatment efficacy. J Antimicrob Chemother 2003, 52:43-49.

15. Faye B, Ndiaye $J$ L, Ndiaye D, Dieng Y, Faye O, Gaye O: Efficacy and tolerability of four antimalarial combinations in the treatment of uncomplicated Plasmodium falciparum malaria in Senegal. Malar J 2007, 6:80.

16. Nfor ENMW, Njifutri N, Mbulli IA, Tawé B, Masumbi NP, Venyoka A: Evaluation de la chimiorésistance à la sulfadoxine-pyrimethamine et des mutations des genes dhfr et dhps dans le district de sante de Ndu au nord-ouest Cameroun. Afr J Sci Tech 2007, 8:52-55.

17. Osman ME, Mockenhaupt FP, Bienzle U, Elbashir MI, Giha HA: Field-based evidence for linkage of mutations associated with chloroquine (pfcrt/ pfmdr1) and sulfadoxine-pyrimethamine (pfdhfr/pfdhps) resistance and for the fitness cost of multiple mutations in P. falciparum. Infect Genet Evol 2007, 7:52-59

18. Wang $P$, Lee CS, Bayoumi R, Djimde A, Doumbo O, Swedberg G, Dao LD, Mshinda H, Tanner M, Watkins WM, Simps PF, Hyde JE: Resistance to antifolates in Plasmodium falciparum monitored by sequence analysis of dihydropteroate synthetase and dihydrofolate reductase alleles in a large number of field samples of diverse origins. Mol Biochem Parasitol 1997, 89:161-177.

19. Mwai L, Kiara SM, Abdirahman A, Pole L, Rippert A, Diriye A, Bull P, Marsh K, Borrmann S, Nzila A: In vitro activities of piperaquine, lumefantrine and dihydroartemisinin in Kenyan Plasmodium falciparum isolates and polymorphisms in pfcrt and pfmdr1. Antimicrob Agents Chemother 2009, 53:5069-5073.

20. Sarr O, Ahouidi AD, Ly O, Daily JP, Ndiaye D, Ndir O, Mboup S, Wirth DF: Mutations in PFCRT K76T do not correlate with sulfadoxine-pyrimethamineamodiaquine failure in Pikine, Senegal. Parasitol Res 2008, 103:765-769.

21. Kublin JG, Cortese JF, Njunju EM, Mukadam RA, Wirima JJ, Kazembe PN, Djimde AA, Kouriba B, Taylor TE, Plowe CV: Reemergence of chloroquine- sensitive Plasmodium falciparum malaria after cessation of chloroquine use in Malawi. J Infect Dis 2003, 187:1870-1875.

22. Mita T, Kaneko A, Lum JK, Bwijo B, Takechi M, Zungu IL, Tsukahara T, Tanabe K, Kobayakawa T, Bjorkman A: Recovery of chloroquine sensitivity and low prevalence of the Plasmodium falciparum chloroquine resistance transporter gene mutation K76T following the discontinuance of chloroquine use in Malawi. Am J Trop Med Hyg 2003, 68:413-415.

23. Figueiredo $P$, Benchimol C, Lopes D, Bernardino L, do Rosario VE, Varandas L, Nogueira F: Prevalence of pfmdr1, pfcrt, pfdhfr and pfdhps mutations associated with drug resistance, in Luanda, Angola. Malar J 2008, 7:236.

24. Mockenhaupt FP, Eggelte TA, Till H, Bienzle U: Plasmodium falciparum pfort and pfmdr1 polymorphisms are associated with the pfdhfr N108 pyrimethamine-resistance mutation in isolates from Ghana. Trop Med Int Health 2001, 6:749-755

25. Mockenhaupt FP, Ehrhardt S, Eggelte TA, Agana-Nsiire P, Stollberg K, Mathieu A, Markert M, Otchwemah RN, Bienzle U: Chloroquine-treatment failure in northern Ghana: roles of pfcrt T76 and pfmdr1 Y86. Ann Trop Med Parasitol 2005, 99:723-732

26. Sinclair DZB, Donegan S, Olliaro P, Garner P: Artemisinin-based combination therapy for treating uncomplicated malaria. Cochrane Database Syst Rev 2009, 3:CD007483.

27. Some AF, Sere YY, Dokomajilar C, Zongo I, Rouamba N, Greenhouse B, Ouedraogo JB, Rosenthal PJ: Selection of known Plasmodium falciparum resistance-mediating polymorphisms by artemether-lumefantrine and amodiaquine-sulfadoxine-pyrimethamine but not dihydroartemisininpiperaquine in Burkina Faso. Antimicrob Agents Chemother 2010, 54:1949-1954

28. Tagbor H, Bruce J, Browne E, Randal A, Greenwood B, Chandramohan D: Efficacy, safety, and tolerability of amodiaquine plus sulphadoxinepyrimethamine used alone or in combination for malaria treatment in pregnancy: a randomised trial. Lancet 2006, 368:1349-1356.

29. Plowe CV, Roper C, Barnwell JW, Happi CT, Joshi HH, Mbacham W, Meshnick SR, Mugittu K, Naidoo I, Price RN, Shafer RW, Sibley CH, Sutherland CJ, Zimmerman PA, Rosenthal PJ: World Antimalarial Resistance Network (WARN) III: molecular markers for drug resistant malaria. Malar J 2007, 6:121.

30. Griffin JT, Cairns M, Ghani AC, Roper C, Schellenberg D, Carneiro I, Newman RD, Grobusch MP, Greenwood B, Chandramohan D, Gosling RD: Protective efficacy of intermittent preventive treatment of malaria in infants (IPTi) using sulfadoxine-pyrimethamine and parasite resistance. PLOS One 2010, 5:e12618.

31. Ishengoma DS, Lwitiho S, Madebe RA, Nyagonde Nyagonde N, Ola Persson $\mathrm{O}$, Vestergaard LS, Bygbjerg IC, Lemnge MM, Alifrangis M: Using rapid diagnostic tests as source of malaria parasite DNA for molecular analyses in the era of declining malaria prevalence. Malar J 2011, 10:6.

32. Cnops L, Boderie M, Gillet P, Van Esbroeck M, Jacobs J: Rapid diagnostic tests as a source of DNA for Plasmodium species-specific real-time PCR Malar J 2011, 10:67.

\section{doi:10.1186/1475-2875-12-137}

Cite this article as: Lo et al:: Prevalence of molecular markers of drug resistance in an area of seasonal malaria chemoprevention in children in Senegal. Malaria Journal 2013 12:137.

\section{Submit your next manuscript to BioMed Central and take full advantage of:}

- Convenient online submission

- Thorough peer review

- No space constraints or color figure charges

- Immediate publication on acceptance

- Inclusion in PubMed, CAS, Scopus and Google Scholar

- Research which is freely available for redistribution 